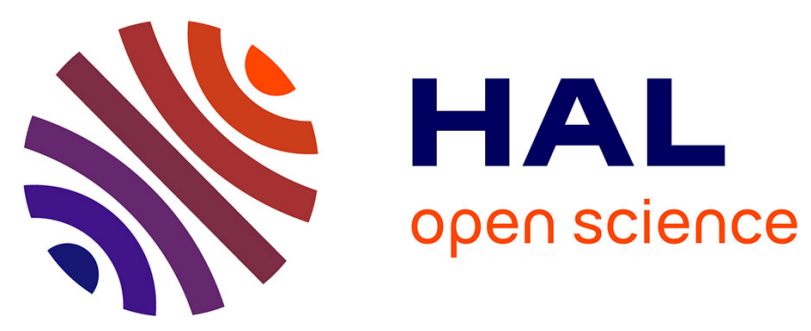

\title{
Risk factors for brain relapse in HER2-positive metastatic breast cancer patients
}

Renata Duchnowska, Rafal Dziadziuszko, Bogumila Czartoryska-Arlukowicz, Barbara Radecka, Barbara Szostakiewicz, Katarzyna Sosińska-Mielcarek, Agnieszka Karpińska, Elżbieta Staroslawska, Tomasz Kubiatowski, Cezary Szczylik

\section{To cite this version:}

Renata Duchnowska, Rafal Dziadziuszko, Bogumila Czartoryska-Arlukowicz, Barbara Radecka, Barbara Szostakiewicz, et al.. Risk factors for brain relapse in HER2-positive metastatic breast cancer patients. Breast Cancer Research and Treatment, 2009, 117 (2), pp.297-303. 10.1007/s10549-0080275-z . hal-00535323

\section{HAL Id: hal-00535323 \\ https://hal.science/hal-00535323}

Submitted on 11 Nov 2010

HAL is a multi-disciplinary open access archive for the deposit and dissemination of scientific research documents, whether they are published or not. The documents may come from teaching and research institutions in France or abroad, or from public or private research centers.
L'archive ouverte pluridisciplinaire HAL, est destinée au dépôt et à la diffusion de documents scientifiques de niveau recherche, publiés ou non, émanant des établissements d'enseignement et de recherche français ou étrangers, des laboratoires publics ou privés. 


\title{
Risk factors for brain relapse in HER2-positive metastatic breast cancer patients
}

\author{
Renata Duchnowska $\cdot$ Rafał Dziadziuszko $\cdot$ Bogumiła Czartoryska-Arłukowicz • \\ Barbara Radecka $\cdot$ Barbara Szostakiewicz $\cdot$ Katarzyna Sosińska-Mielcarek · \\ Agnieszka Karpińska · Elżbieta Starosławska · Tomasz Kubiatowski · \\ Cezary Szczylik
}

Received: 8 October 2008/ Accepted: 9 December 2008/Published online: 7 January 2009

(C) Springer Science+Business Media, LLC. 2009

\begin{abstract}
Brain relapse is a common occurrence in HER2positive breast cancer patients. However, the factors determining the risk of brain metastasis in these patients remain to be established. The aim of this study was to assess the impact of particular clinical and pathological factors on the risk of brain relapse in HER2-positive advanced breast cancer patients. The study group included 264 consecutive HER-2 positive metastatic breast cancer patients, most of whom (210; $80 \%$ ) were administered trastuzumab, usually in combination with chemotherapy. Time from the diagnosis to distant relapse ranged from 0 to 142 months (median 16 months). The most common dominant site of metastatic disease was viscera $(80 \%)$, followed by soft tissue (11\%) and bones (10\%). After a median follow-up of 3.1 years, the symptomatic brain relapse occurred in 103 patients (39\%). Median time from treatment
\end{abstract}

Presented in part in oral form at the 2007 European Cancer Conference, Barcelona, Spain.

R. Duchnowska $(\bowtie) \cdot$ C. Szczylik

Department of Oncology, Military Institute of Medicine,

Warsaw, Ul. Szaserów 128, 00-908 Warsaw, Poland

e-mail: rdtt@wp.pl

R. Dziadziuszko · B. Szostakiewicz · K. Sosińska-Mielcarek Medical University of Gdańsk, Gdańsk, Poland

B. Czartoryska-Arłukowicz

Regional Cancer Center, Białystok, Poland

B. Radecka

Regional Oncology Center, Opole, Poland

\author{
A. Karpińska \\ Regional Oncology Hospital, Szczecin, Poland \\ E. Starosławska $\cdot$ T. Kubiatowski \\ Regional Oncology Center, Lublin, Poland
}

dissemination to brain relapse was 15 months (range, 0-81 months), and the cumulative 1-year, 3-year and 5-year risk of brain relapse was 17,42 and $55 \%$, respectively. The average annual risk of brain relapse for surviving patients during consecutive 7 years of follow-up was $10.0 \%$ (95\% CI, $6.6-13.5 \%)$. In the univariate analysis the only variable significantly related to the increased risk of brain relapse was time from initial diagnosis to distant relapse shorter than 2 years $(\mathrm{HR}=1.55,95 \% \mathrm{CI}, 1.03-2.33, \quad P=0.034)$. Patients with dominant site of disease in soft tissue or bones tended to have lower risk of relapse ( $\mathrm{HR}=0.54$ and 0.62 ; $P=0.098$ and 0.203 , respectively) compared to patients with visceral metastases. Treatment with trastuzumab was not associated with reduced risk of brain relapse $(\mathrm{HR}=0.91$, 95\% CI, 0.47-1.77, $P=0.78$ ). In the multivariate analysis, time from initial diagnosis to distant relapse shorter than 2 years remained the only significant variable related to increased risk of brain relapse (adjusted $\mathrm{HR}=1.62,95 \% \mathrm{CI}$, 1.07-2.44; $P=0.022$ ). HER2-positive breast cancer patients remain at high and continuous risk of brain relapse for a prolonged period of time after diagnosis of disease dissemination. Short time from initial diagnosis to distant relapse is related to increased risk of brain relapse. Molecular predictors are sorely needed to better characterize patients with high probability of early brain relapse.

Keywords Brain relapse - HER2-positive breast cancer . Trastuzumab $\cdot$ Brain-blood barrier

\section{Introduction}

Brain is among the most common sites of relapse in breast cancer, with the clinical and autopsy occurrence of 14-20\% and $18-30 \%$, respectively $[1,2]$. Relapse in the brain is 
related to high morbidity and mortality, with relatively few effective therapeutic options. This issue has emerged as an important clinical problem, since most cytotoxic agents used in breast cancer do not cross the blood-brain barrier, making brain a sanctuary site for the development of metastasis. Additionally, increased efficacy of systemic treatment in extracranial sites may allow more time for the development of brain metastasis. Indeed, some recent studies suggested increased risk of brain relapse in breast cancer patients administered taxanes and anthracyclines, the two most effective groups of anticancer agents in this malignancy [3, 4]. Another factor contributing to increasing occurrence of brain lesions are refined imaging methods, providing more effective detection.

Several studies demonstrated increased risk of brain relapse in breast cancer patients with overexpressed or amplified HER2-neu gene [5-8]. HER2 abnormalities occur in $20-30 \%$ of invasive breast cancers and are associated with more aggressive tumor growth, increased risk of relapse and shorter survival $[9,10]$. Currently HER2-positive breast cancer patients are managed with trastuzumab, a monoclonal antibody against extracellular domain of HER2 receptor. Trastuzumab does not cross through the blood-brain barrier and is ineffective in preventing and treating brain lesions [11-17]. Recently, Food and Drug Administration (FDA) and European Medicines Agency (EMEA) granted approval to lapatinib, an anti-HER2 small-molecule tyrosine kinase inhibitor, for use in women with advanced HER2-positive breast cancer who have progressed on trastuzumab treatment.

In most instances brain metastases in breast cancer patients appear after another systemic disease has developed at other sites. With the increased treatment efficacy of extracranial lesions, poor control of brain lesions may largely influence prognosis. For example, in a recent series including metastatic breast cancer patients treated with trastuzumab, nearly half of deaths were due to progressive brain disease [11]. It is hoped that determining tumor and host risk factors for brain metastasis might allow selection of candidates for preventive strategies. Most studies addressing risk factors for brain relapse included unselected breast cancer patients [18-22], whereas little is known on this issue in HER2-positive breast cancer patients [23, 24]. In this study we assessed retrospectively the impact of selected clinical and pathological variables on the risk of brain relapse in a large, unselected group of patients with metastatic HER2-positive breast cancer.

\section{Materials and methods}

\section{Patients}

This series included 264 consecutive HER2-positive (immunohistochemistry $3+$ or FISH-positive) pathologically confirmed metastatic breast cancer patients treated in six oncology centers between 1993 and 2007 (Table 1). Tumor diagnosis and cancer type were determined by two independent pathologists. Expression of estrogen and progesterone receptors was determined using immunohistochemistry, with $10 \%$ of nuclear staining considered as a positive result. HER2 protein expression was determined using semiquantitative immunohistochemistry (HercepTest, Dako A/S, Glostrup, Denmark). Only samples showing strong expression (scored 3+), defined as uniform, intense membrane staining of at least $10 \%$ of invasive tumor cells, were considered positive. The samples showing intermediate expression (scored 2+) were subjected to additional analysis of gene HER 2 copy number using fluorescence in situ hybridization (FISH). Gene amplification by FISH was defined as a FISH ratio (HER2/centromeric probe for chromosome 17 ratio) of more than 2.0. FISH-positive patients were considered HER2positive. Due to the retrospective nature of this study, tumor staging was performed using AJCC/UICC classification from 1997. Metastatic lesions were grouped into three categories: soft tissue, bones and viscera. For tumors involving more than one category, dominant site of distant disease was classified by the category associated with the worst prognosis, irrespective of the extent of involvement, in the following order of increasing gravidity: soft tissue, bones, viscera.

Seventy-two percent of the patients relapsed after previous curative surgery, and the remaining $28 \%$ were inoperable at the time of diagnosis (Table 1). Postoperative radiotherapy was applied in 93 patients $(49 \%$ of those subjected to surgery). A total of 210 patients $(80 \%)$ were administered trastuzumab for metastatic disease, usually in combination with chemotherapy. No patient received trastuzumab in the adjuvant setting. The time from the initial diagnosis to distant relapse ranged from 0 to 142 months (median 16 months). No screening for occult brain lesions was performed, therefore all metastases were symptomatic.

\section{Statistical analysis}

Continuous variables were described using the group size, variable mean or median and range. Qualitative variables were compared by chi-square test and exact Fisher's test, where appropriate. Median follow-up was calculated in accordance with Schemper and Smith [25]. Time to progression, time to brain relapse, and overall survival were estimated by the Kaplan-Meier method and compared using univariate log-rank tests. Hazard ratios and $95 \%$ confidence intervals for particular variables were calculated using univariate Cox's proportional model; reported $P$ values were derived from Wald's test. Multivariate analysis was done with backward manual elimination based on likelihood-ratio statistics. Cumulative risk of 
Table 1 Patent characteristics $(n=264)^{\mathrm{a}}$

\begin{tabular}{|c|c|}
\hline Variable & $n(\%)$ \\
\hline \multicolumn{2}{|l|}{ Menopausal status } \\
\hline Premenopausal & $131(50 \%)$ \\
\hline Postmenopausal & $130(49 \%)$ \\
\hline Unknown & $3(1 \%)$ \\
\hline \multicolumn{2}{|l|}{ Age at diagnosis (years) } \\
\hline Mean & 49 \\
\hline Range & $24-77$ \\
\hline \multicolumn{2}{|l|}{ Dominant site of disease } \\
\hline Visceral & $210(80 \%)$ \\
\hline Soft tissue & $28(11 \%)$ \\
\hline Bones & $26(10 \%)$ \\
\hline \multicolumn{2}{|l|}{ Steroid receptor status } \\
\hline $\mathrm{ER}+/ \mathrm{PgR}+$ & $57(22 \%)$ \\
\hline $\mathrm{ER}+/ \mathrm{PgR}-$ & $39(15 \%)$ \\
\hline $\mathrm{ER}-/ \mathrm{PgR}+$ & $12(5 \%)$ \\
\hline $\mathrm{ER}-/ \mathrm{PgR}-$ & $144(55 \%)$ \\
\hline Unknown & $12(5 \%)$ \\
\hline \multicolumn{2}{|l|}{ Pathology type } \\
\hline Ductal & $210(80 \%)$ \\
\hline Lobular & $16(6 \%)$ \\
\hline Ductal and lobular & $9(3 \%)$ \\
\hline Other & $8(3 \%)$ \\
\hline Not specified & $21(8 \%)$ \\
\hline \multicolumn{2}{|l|}{ Grade } \\
\hline G1 & $4(2 \%)$ \\
\hline $\mathrm{G} 2$ & $87(33 \%)$ \\
\hline G3 & $100(38 \%)$ \\
\hline Not specified & $73(28 \%)$ \\
\hline \multicolumn{2}{|l|}{ Surgery } \\
\hline Modified radical mastectomy & $183(69 \%)$ \\
\hline Breast conservation & $8(3 \%)$ \\
\hline None & $73(28 \%)$ \\
\hline \multicolumn{2}{|l|}{ Chemotherapy $^{\mathrm{b}}$} \\
\hline Induction only & $15(8 \%)$ \\
\hline Adjuvant only & $83(43 \%)$ \\
\hline Induction and adjuvant & $74(39 \%)$ \\
\hline None & $19(10 \%)$ \\
\hline \multicolumn{2}{|l|}{ Adjuvant endocrine therapy ${ }^{\mathrm{b}}$} \\
\hline Tamoxifen & $78(41 \%)$ \\
\hline Aromatase inhibitors & $3(2 \%)$ \\
\hline Tamoxifen and aromatase inhibitors & $13(7 \%)$ \\
\hline None & $97(51 \%)$ \\
\hline Adjuvant radiotherapy ${ }^{\mathrm{b}}$ & $93(49 \%)$ \\
\hline Trastuzumab for advanced disease & $210(80 \%)$ \\
\hline
\end{tabular}

${ }^{\text {a }}$ Percentages may not sum up to 100 due to rounding

${ }^{\mathrm{b}}$ Only in patients subjected to surgery brain relapse was calculated using cause-specific hazard method with deaths considered as censored events [26]. We additionally performed cumulative incidence analysis using competing risk model with deaths as competing events [26]. The model was based on the assumption that longer survival of patients treated with trastuzumab may have resulted in higher chance of observing brain relapse. All reported tests were two-sided with significance level of $\alpha=0.05$, with no adjustments for multiple comparisons. All calculations were performed using SPSS for Windows version 13.0 (SPSS Inc., Chicago, IL) and NCSS 2001 (NCSS Inc., Kaysville, UT).

\section{Results}

The median follow-up from the diagnosis of disease dissemination was 3.1 years (range, $0-11.4$ years). 1-year and 2-year survival probabilities were $82 \%$ (95\% confidence interval $[\mathrm{CI}], 77-86 \%)$ and $66 \%$ (95\% CI, 60-72\%), respectively. Symptomatic brain relapse occurred in 103 patients $(39 \%)$. Seventeen patients $(6 \%)$ presented with brain metastases at the time of dissemination occurrence. Median time from disease dissemination to brain relapse was 15 months (range, 0-81 months). Cumulative 1-year, 3 -year and 5-year risk of brain relapse was $17 \%(95 \% \mathrm{CI}$, $13-22 \%), 42 \%(95 \% \mathrm{CI}, 35-49 \%)$ and $55 \%(95 \% \mathrm{CI}$, 46-64\%), respectively (Fig. 1). Cumulative hazard function of brain relapse was constant with time (data not shown). When 17 patients in whom first distant relapse

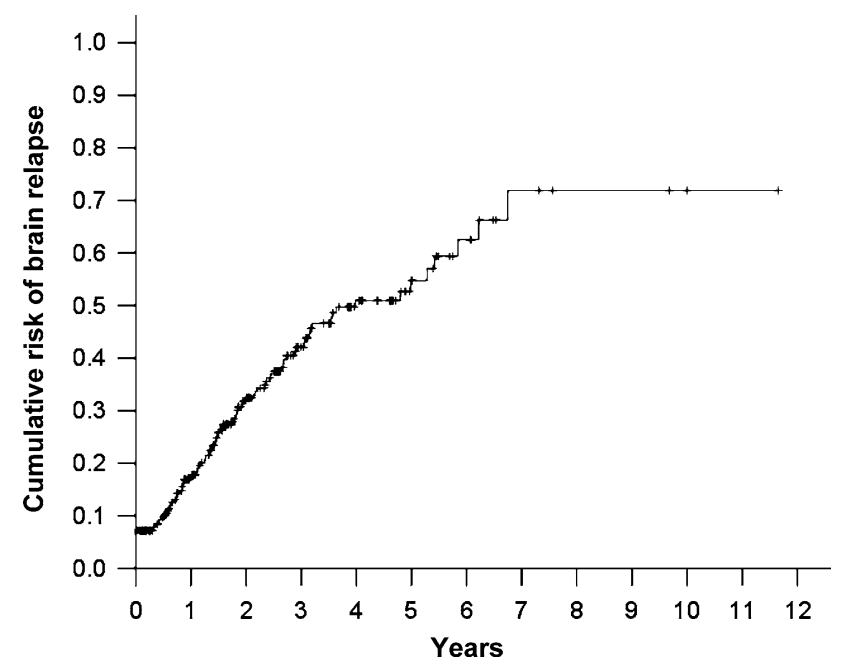

Fig. 1 Cumulative risk of brain relapse. Median time from disease dissemination to brain relapse: 15 months; cumulative 1-year, 3-year and 5-year risk of brain relapse: 17,42 and $55 \%$, respectively 
included brain metastases were excluded from the analysis, the average annual risk of brain relapse for surviving patients during consecutive 7 years of follow-up was $10.0 \%$ (95\% CI, 6.6-13.5\%).

In the univariate analysis the only variable significantly related to the increased risk of brain relapse was time from initial diagnosis to distant relapse shorter than 2 years $(\mathrm{HR}=1.55,95 \%$ CI, $1.03-2.33 ; P=0.034 ;$ Table 2; Fig 2). Cumulative 1-year and 3-year risk of brain relapse in postmenopausal patients was $15 \%(95 \% \mathrm{CI}, 8-22 \%)$ and $37 \%(26-48 \%)$, compared to $19 \%(13-25 \%)$ and $45 \%$ $(36-55 \%)$ in premenopausal patients, respectively. Patients with dominant site of disease in soft tissue or bones tended to have lower risk of relapse $(\mathrm{HR}=0.54$ and 0.62 , respectively; $P=0.098$ and 0.203 , respectively) compared to patients with visceral metastases. Administration of trastuzumab was not associated with reduced risk of brain metastases $(\mathrm{HR}=0.91,95 \% \mathrm{CI}, 0.47-1.77, P=0.78$; Table 2; Fig. 3). In the multivariate analysis, time to distant relapse from initial diagnosis shorter than 2 years remained the only significant variable related to increased risk of brain relapse $(\mathrm{HR}=1.62,95 \% \mathrm{CI}, 1.07-2.44$; $P=0.022$; adjusted for histology, age and dominant site of disease). We also performed supplementary univariate analysis of risk factors for early brain relapse (within 3 years) by censoring all patients who survived without brain relapse for longer than 3 years. Results of this analysis were similar to those presented in Table 2.

In the competing risk analysis with deaths as censored events, the cumulative risk of brain relapse was similar in patients who did and did not receive trastuzumab, with a 3 -year incidence of brain relapse of 20\% (95\%CI: 15-27\%) and 29\% (19-46\%), respectively (figure not shown).

\section{Discussion}

Our study included a large series of HER2-positive advanced breast cancer patients, with relatively long follow-up. Cumulative 3-year risk of brain relapse of $42 \%$ is in the range found in other series of HER2-positive advanced breast cancer patients [11-17, 23]. In this cohort the average annual risk of symptomatic brain relapse for surviving patients during consecutive 7 years of follow-up was $10 \%$, with no apparent plateau. Thus, HER2-positive advanced breast cancer patients remain at high and continuous risk of brain relapse for a prolonged period of time after diagnosis of disease dissemination, and the development of brain metastasis in this group appears to be a stochastic event.

High incidence of brain relapse in HER2-positive patients has been attributed to aggressive behavior of this subtype, including more rapid cell proliferation, increased
Table 2 The risk of brain relapse according to clinicopathological variables: univariate analysis

\begin{tabular}{|c|c|c|c|}
\hline Variable & HR & $95 \% \mathrm{CI}$ & $P$ \\
\hline \multicolumn{4}{|l|}{ Menopausal status } \\
\hline Postmenopausal & 1.00 & & \\
\hline Premenopausal & 1.12 & $0.76-1.67$ & 0.56 \\
\hline Age (continuous variable) & 0.99 & $0.97-1.01$ & 0.52 \\
\hline \multicolumn{4}{|l|}{ Pathology type } \\
\hline Non-lobular & 1.00 & & \\
\hline Lobular & 1.26 & $0.69-2.30$ & 0.45 \\
\hline \multicolumn{4}{|l|}{ Grade } \\
\hline G1 & NA & NA & NA \\
\hline $\mathrm{G} 2$ & 1.00 & & \\
\hline G3 & 0.95 & $0.60-1.49$ & 0.81 \\
\hline \multicolumn{4}{|l|}{ Time to distant relapse } \\
\hline$>2$ years & 1.00 & $1.03-2.33$ & 0.034 \\
\hline$\leq 2$ years & 1.55 & & \\
\hline \multicolumn{4}{|l|}{ Dominant site of disease } \\
\hline Viscera & 1.00 & & \\
\hline Soft tissue & 0.54 & $0.26-1.12$ & 0.098 \\
\hline Bone & 0.62 & $0.30-1.29$ & 0.203 \\
\hline \multicolumn{4}{|l|}{ ER } \\
\hline Negative & 1.00 & & \\
\hline Positive & 0.82 & $0.55-1.23$ & 0.34 \\
\hline \multicolumn{4}{|l|}{ PR } \\
\hline Negative & 1.00 & & \\
\hline Positive & 0.95 & $0.61-1.47$ & 0.81 \\
\hline \multicolumn{4}{|l|}{ Trastuzumab therapy ${ }^{\mathrm{a}}$} \\
\hline No & 1.00 & & \\
\hline Yes & 0.91 & $0.47-1.77$ & 0.78 \\
\hline
\end{tabular}

angiogenesis, deficient apoptosis and increased metastasis formation $[9,10]$. It is therefore possible that this phenotype also predisposes to brain metastasis. However, HER2positive tumors may also have a specific predilection to central nervous system (CNS). Indeed, some studies demonstrated that CNS environment may facilitate migration and settling of HER2-positive cells [27, 28]. Recently, overexpression of HER2 has been found to increase the colonization of breast cancer cells in the brain in vivo [29].

The risk factors for the development of brain relapse in general breast cancer patient populations include younger age, aggressive tumor growth, dissemination to other distant sites and steroid receptor negativity [18-22]. The knowledge of the risk factors for brain relapse in a subset of HER2-positive advanced breast cancer patients has been limited, and our study is among the few investigating this issue $[23,24]$. In the present analysis the only variable 


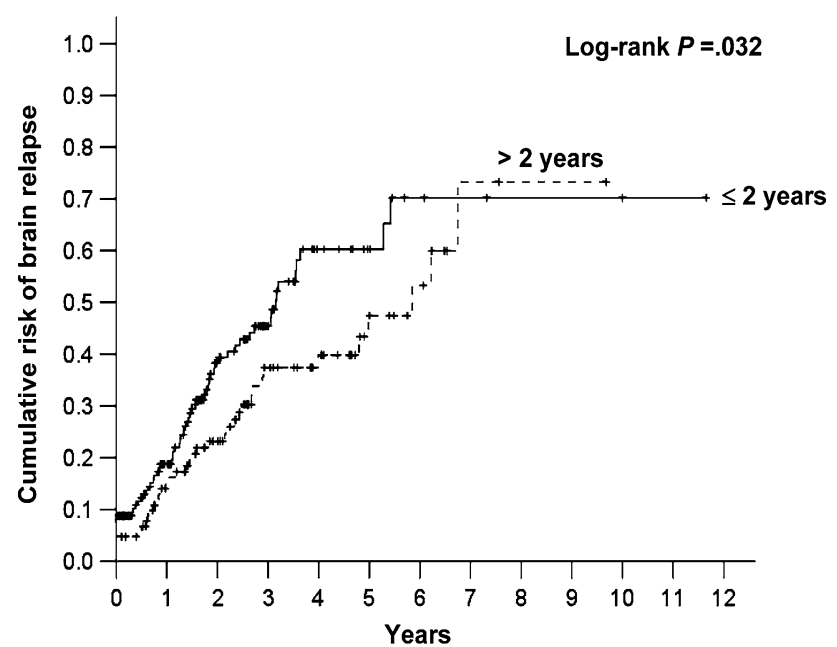

Fig. 2 Cumulative risk of brain relapse according to time from initial diagnosis to dissemination. Hazard ratio for patients with diagnosis to distant relapse interval $\leq 2$ years:1.55 (95\% CI, 1.03-2.33; $P=$ 0.034; univariate analysis)

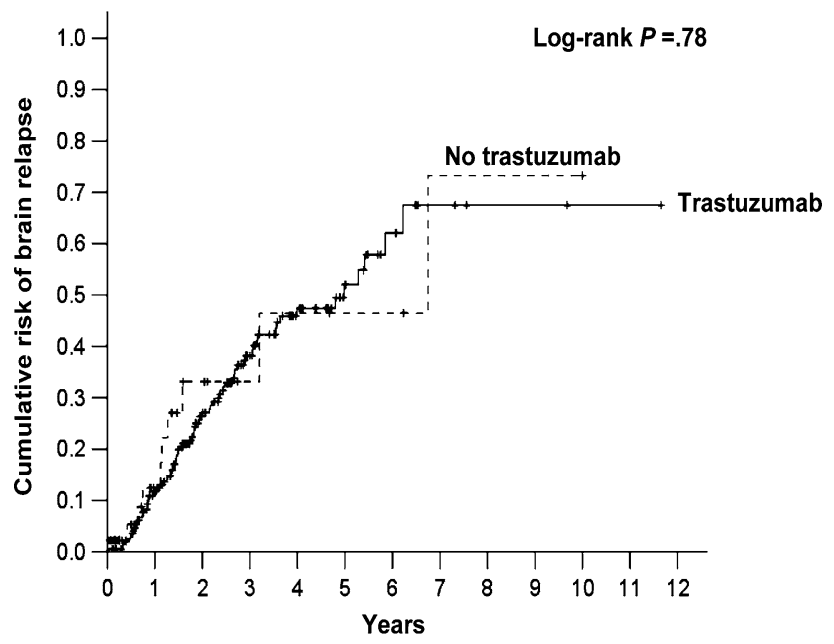

Fig. 3 Cumulative risk of brain relapse according to trastuzumab therapy. Hazard ratio for patients who received trastuzumab: 0.91 (95\% CI, 0.47-1.77, $P=0.78$; univariate analysis)

significantly related to the increased risk of brain relapse was short time from initial diagnosis to distant relapse, a well established indicator of tumor aggressiveness. In the earlier analysis performed on this series of patients, after a shorter follow-up and with lower cumulative incidence of brain relapse $(28 \%)$, also premenopausal status was found to be significantly related to the risk of brain relapse, whereas lobular carcinoma was at borderline level [30]. With longer follow-up, during which several new events occurred (a cumulative incidence of 39\%), these two additional factors have lost their significance.

In this series the steroid receptor status and tumor grade were not related to the risk of brain relapse. The lack of steroid receptor expression is considered an adverse prognostic factor in general breast cancer population, and also includes increased risk of brain relapse [18-22, 31]. The knowledge on the predictive value of steroid receptor status for brain metastases in HER2-positive advanced breast cancer patients is scarce. A recent study including patients administered trastuzumab did not demonstrate any association between ER status and the risk of brain relapse [17]. Pathological tumor grade in general breast cancer population is considered highly predictive for clinical behavior of breast cancer, including the risk of brain relapse [18]; however, the impact of this feature in HER2positive patients is also not well recognized. Of note, typically for HER2-positive advanced breast cancers, our material included only a small proportion $(2 \%)$ of well differentiated tumors. Visceral metastases in breast cancer are known to carry particularly ominous prognosis $[18,21]$. In our material patients with dominant site of disease in soft tissue or bones had indeed lower risk of relapse compared to patients with visceral metastases. However, this difference did not reach statistical significance, probably due to the low number of patients in the two former subsets. Notably, this study included exclusively patients with earlier tumor dissemination, by definition selected by adverse prognostic factors. It is likely therefore that in such a selected group well established prognostic factors might have been confounded.

An important finding of the present study was no impact of trastuzumab therapy on the risk of brain relapse. The small number of patients not administered trastuzumab calls for cautious interpretation of this result, nevertheless resistance of brain lesions to trastuzumab therapy was consistently reported by others. Notably, several studies demonstrated the development of brain metastases despite the response to trastuzumab in extracranial sites, and no prophylactic effect of trastuzumab on brain relapse both in advanced disease and in the adjuvant setting [11-17]. Brain is the sole site of progression in about $10 \%$ of advanced breast cancer patients administered trastuzumab [16]. The most likely explanation for the inefficacy of trastuzumab to prevent brain metastases is impaired penetration of this drug through the blood-brain barrier due to the high molecular weight (145 kDa) of this antibody [32, 33].

Interestingly, despite ineffective delivery of trastuzumab imposed by the blood-brain barrier, some studies suggested that prolonged survival may also include patients who developed brain relapse while on therapy with this agent [14, 24, 34-39]. For example, in the study of Lower et al. [14] the mean survival in patients who developed brain relapse during trastuzumab therapy was 1,400 days, compared to 639 days in patients with brain relapse who were not applied this agent. Additionally, in that study the incidence of bone relapse in patients administered trastuzumab was significantly lower compared to those who did 
not receive this compound (15 and 91\%, respectively). However, other studies did not demonstrate survival benefit of trastuzumab in patients with brain relapse $[16,40]$.

The median survival in this series was 3.2 years and the median survival from the diagnosis of brain relapse9 months. Despite adverse prognostic impact of HER2 overexpression or amplification, these results seem to be better compared to those reported previously in unselected series of advanced breast cancer [41-43]. This may be related to more effective systemic therapy of advanced breast cancer, particularly the use of trastuzumab, more effective management of brain metastases and improved supportive care.

Our study demonstrated the limited value of clinical and pathological factors in predicting brain relapse in advanced HER2-positive advanced breast cancer. Future studies on prediction of this event should include tests based on molecular tumor characteristics. Discovery of such tests can be envisioned on DNA level (comparative genomic hybridization arrays), RNA level (mRNA and microRNA profiling using array technology) and protein level (proteomics using mass spectrometry). These methods have already been found to better predict treatment outcome in breast cancer patients compared to standard clinicopathological factors [44, 45]. Most recently, we have developed a 13-gene molecular signature highly predictive for early brain relapse [46]. We believe that further refinement of molecular methods may identify categories of metastatic breast cancer patients with particularly high risk of brain relapse, in whom preventive strategies might be considered.

Acknowledgments The authors wish to thank Prof. Jacek Jassem for his contribution to study design, interpretation of results and numerous helpful discussions on the manuscript.

\section{References}

1. Flowers A, Levin VA (1993) Management of brain metastases from breast carcinoma. Oncology 7:21-26

2. Tsukada Y, Fouad A, Pickren JW, Lane WW (1983) Central nervous system metastasis from breast carcinoma. Autopsy study. Cancer 52:2349-2354. doi:10.1002/1097-0142(19831215)52:12 $<2349$ ::AID-CNCR2820521231>3.0.CO;2-B

3. Freilich RJ, Seidman AD, DeAngelis LM (1995) Central nervous system progression of metastatic breast cancer in patients treated with paclitaxel. Cancer 76:232-236. doi:10.1002/1097-0142 $>(19950715) 76: 2<232::$ AID-CNCR2820760212>3.0.CO;2-0

4. Crivellari D, Pagani O, Veronesi A et al (2001) High incidence of central nervous system involment in patients with metastatic or locally advanced breast cancer treated with epirubicin and docetaxel. Ann Oncol 12:353-356. doi:10.1023/A:1011132609055

5. Miller KD, Weathers T, Haney LG et al (2003) Occult central nervous system involvement in patients with metastatic breast cancer: prevalence, predictive factors and impact on survival. Ann Oncol 14:1072-1077. doi:10.1093/annonc/mdg300
6. Kallioniemi OP, Holli K, Visakorpi T, Koivula T, Helin HH, Isola J (1991) Association of c-erbB-2 protein over-expression with high rate of cell proliferation, increased risk of visceral metastasis and poor long-term survival in breast cancer. Int $\mathbf{J}$ Cancer 49:650-655. doi:10.1002/ijc.2910490504

7. Altaha R, Crowell E, Hobbs G, Higa G, Abraham J (2005) Increased risk of brain metastases in patients with HER-2/neupositive breast carcinoma. Cancer 103:442-443. doi:10.1002/ cncr.20813

8. Gabos Z, Sinha R, Hanson J et al (2006) Prognostic significance of human epidermal growth factor receptor positivity for the development of brain metastasis after newly diagnosed breast cancer. J Clin Oncol 24:5658-5663. doi:10.1200/JCO.2006. 07.0250

9. Hynes NE, Stern DF (1994) The biology of erbB-2/neu/HER2 and its role in cancer. Biochim Biophys Acta 1198:165-184

10. Revillion F, Bonneterre J, Peyrat JP (1998) ERBB2 oncogene in human breast cancer and its clinical significance. Eur J Cancer 34:791-808. doi:10.1016/S0959-8049(97)10157-5

11. Bendell JC, Domchek SM, Burstein HJ et al (2003) Central nervous system metastases in women who receive trastuzumabbased therapy for metastatic breast carcinoma. Cancer 97:29722977. doi:10.1002/cncr.11436

12. Clayton AJ, Danson S, Jolly S et al (2004) Incidence of cerebral metastases in patients treated with trastuzumab with trastuzumab for metastatic breast cancer. Br J Cancer 91:639-643

13. Shmueli E, Wigler N, Inbar M (2004) Central nervous system progression among patients with metastatic breast cancer responding to trastuzumab treatment. Eur J Cancer 40:379-382. doi:10.1016/j.ejca.2003.09.018

14. Lower EE, Drosick RD, Blau R, Brennan L, Danneman W, Hawley DK (2003) Increased rate of brain metastases with trastuzumab therapy not associated with impaired survival. Clin Breast Cancer 4:114-119. doi:10.3816/CBC.2003.n.016

15. Lai R, Dang CT, Malkin MG, Abrey LE (2004) The risk of central nervous system metastases after trastuzumab therapy in patients with breast carcinoma. Cancer 15:810-816. doi:10.1002/ cncr.20418

16. Burstein HJ, Lieberman G, Slamon DJ, Winer EP, Klein P (2005) Isolated central nervous system metastases in patients with HER2 overexpressing advanced breast cancer treated with first-line trastuzumab based therapy. Ann Oncol 16:1772-1777. doi:10.1093/ annonc/mdi371

17. Yau T, Swanton C, Chua S et al (2006) Incidence, pattern and timing of brain metastases among patients with advanced breast cancer treated with trastuzumab. Acta Oncol 45:196-201

18. Pestalozzi BC, Zahrieh D, Price KN, International Breast Cancer Study Group(IBCSG) et al (2006) Identifying breast cancer patients at risk for Central Nervous System (CNS) metastases in trials of the International Breast Cancer Study Group (IBCSG). Ann Oncol 17:935-944. doi:10.1093/annonc/md1064

19. Nam BH, Kim SY, Han HS et al (2008) Breast cancer subtypes and survival in patients with brain metastases. Breast Cancer Res 10:R20. doi:10.1186/bcr1870

20. Sparrow GE, Rubens RD (1981) Brain metastases from breast cancer: clinical course, prognosis and influence of treatment. Clin Oncol 7:291-301

21. Patanaphan V, Salazar OM, Risco R (1988) Breast cancer: metastatic patterns and their prognosis. South Med J 81:1109-1112

22. Tham YL, Sexton K, Kramer R, Hilsenbeck S, Elledge R (2006) Primary breast cancer phenotypes associated with propensity for central nervous system metastases. Cancer 107:696-704. doi:10.1002/cncr.22041

23. Stemmler HJ, Kahlert S, Siekiera W, Untch M, Heinrich B, Heinemann V (2006) Characteristics of patients with brain metastases receiving trastuzumab for HER2 overexpressing 
metastatic breast cancer. Breast 15:219-225. doi:10.1016/ j.breast.2005.04.017

24. Gori S, Rimondini S, De Angelis V et al (2007) Central nervous system metastases in HER-2 positive metastatic breast cancer patients treated with trastuzumab: incidence, survival, and risk factors. Oncologist 12:766-773. doi:10.1634/theoncologist.12-7-766

25. Schemper M, Smith TL (1996) A note of quantifying follow-up in studies of failure time. Control Clin Trials 17:343-346. doi:10.1016/0197-2456(96)00075-X

26. Pintilie $M$ (2007) Analysing and interpreting competing risk data. Stat Med 26:1360-1367. doi:10.1002/sim.2655

27. Li Y, Pan Y, Wei Y et al (2004) Upregulation of CXCR4 is essential for HER2-mediated tumor metastasis. Cancer Cell 6:459-469. doi:10.1016/j.ccr.2004.09.027

28. Kauraniemi P, Bärlund M, Monni O, Kallioniemi A (2001) New amplified and highly expressed genes discovered in ERBB2 amplicon in breast cancer by cDNA microarrays. Cancer Res 61:8235-8240

29. Palmieri D, Bronder JL, Herring JM et al (2007) Her-2 overexpression increases the metastatic outgrowth of breast cancer cells in the brain. Cancer Res 67:4190-4198. doi:10.1158/00085472.CAN-06-3316

30. Duchnowska R, Czartoryska-Arlukowicz B, Radecka B et al (2007) Prediction of brain relapse (BR) in HER-2 positive metastatic breast cancer (MBC) patients. Eur J Cancer Suppl 5:213. doi:10.1016/S1359-6349(07)70862-5

31. Samaan NA, Buzdar AU, Aldinger KA et al (1981) Estrogen receptor: a prognostic factor in breast cancer. Cancer 47:554-560. doi:10.1002/1097-0142(19810201)47:3<554::AID-CNCR28204 70322>3.0.CO;2-W

32. Su Y, Sinko PJ (2006) Drug delivery across the blood-brain barrier: why is it difficult? How to measure and improve it? Expert Opin Drug Deliv 3:419-435. doi:10.1517/17425247. 3.3.419

33. Neuwelt E (2004) Mechanisms of disease: The blood-brain barrier. Neurosurgery 54:131-142. doi:10.1227/01.NEU.00000 97715.11966.8E

34. Dawood S, Broglio K, Esteva FJ et al (2008) Defining prognosis for women with breast cancer and CNS metastases by HER2 status. Ann Oncol 19:1242-1248. doi:10.1093/annonc/mdn036

35. Park IH, Ro J, Lee KS, Nam BH, Kwon Y, Shin KH (2008) Trastuzumab treatment beyond brain progression in
HER2-positive metastatic breast cancer. Ann Oncol. doi:10.1093/ annonc/mdn539

36. Metro G, Sperduti I, Russillo M, Milella M, Cognetti F, Fabi A (2007) Clinical utility of continuing trastuzumab beyond brain progression in HER-2 positive metastatic breast cancer. Oncologist 12:1467-1469. doi:10.1634/theoncologist.12-12-1467

37. Kirsch DG, Ledezma CJ, Mathews CS et al (2005) Survival after brain metastases from breast cancer in the trastuzumab era. J Clin Oncol 23:2114-2116. doi:10.1200/JCO.2005.05.249

38. Eichler AF, Kuter I, Ryan P, Schapira L, Younger J, Henson JW (2008) Survival in patients with brain metastases from breast cancer: the importance of HER-2 status. Cancer 112:2359-2367. doi: $10.1002 /$ cncr. 23468

39. Church DN, Modgil R, Guglani S et al (2008) Extended survival in women with brain metastases from HER2 overexpressing breast cancer. Am J Clin Oncol 31:250-254

40. Fuchs IB, Loebbecke M, Buhler H et al (2002) HER 2 in brain metastases: issues of concordance, survival, and treatment. J Clin Oncol 20:4130-4133. doi:10.1200/JCO.2002.04.016

41. DiStefano A, Yong Yap Y, Hortobagyi GN, Blumenschein GR (1979) The natural history of breast cancer patients with brain metastases. Cancer 44:1913-1918. doi:10.1002/1097-0142 (197911)44:5<1913::AID-CNCR2820440554>3.0.CO;2-D

42. Lentzsch S, Reichardt P, Weber F, Budach V, Dörken B (1999) Brain metastases in breast cancer: prognostic factors and management. Eur J Cancer 35:580-585. doi:10.1016/S0959-8049 (98)00421-3

43. Fokstuen T, Wiking N, Rutqvist LE et al (2000) Radiation therapy in the management of brain metastases from breast cancer. Breast Cancer Res Treat 62:211-216. doi:10.1023/ A: 1006486423827

44. Sorlie T, Perou CM, Tibshirani R et al (2001) Gene expression patterns of breast carcinomas distinguish tumor subclasses with clinical implications. Proc Natl Acad Sci USA 98:10869-10874. doi:10.1073/pnas.191367098

45. van de Vijver MJ, He YD, van't Veer LJ et al (2002) A geneexpression signature as a predictor of survival in breast cancer. $\mathrm{N}$ Engl J Med 347:1999-2009. doi:10.1056/NEJMoa021967

46. Duchnowska R, Jassem J, Thorat MA et al (2008) Gene expression analysis for prediction of early brain metastasis (BM) in HER2-positive (HER2+) breast cancer patients (pts). J Clin Oncol 26(suppl):45s 